\title{
World Health Assembly tackles air pollution
}

$\mathrm{T}$ he World Health Assembly approved the first international resolution aimed at combatting air pollution among the 194 member states of the World Health Organization (WHO) on May 26.

Eight million deaths globally are attributed to air pollution annually, a number that is only increasing, says Dr. Maria Neira, director of the WHO's Public Health and the Environment Department. "Air pollution represents, today, if not the biggest, then one of the biggest health challenges that we have in front of us, and we are very much committed in WHO to take all the action needed."

Much of that action will focus on high levels of fine particulate matter that comes from burning fossil fuels, mainly in motor vehicles, but also in factories and power plants. When inhaled, fine particulate matter is small enough to enter the bloodstream through the lung's alveoli. Of deaths due to outdoor air pollution, $80 \%$ are attributed to heart disease and stroke, and $20 \%$ to respiratory illnesses and cancers, according to a document released by the WHO on Apr. 10.

The WHO guideline for fine particulate matter, which was set a decade ago, is a mean of $10 \mu \mathrm{g} / \mathrm{m}^{3}$ annually. However, low-income countries are nowhere near meeting these standards.

According to the WHO, Delhi is the most polluted city in the world, with an annual mean of fine particulate matter of $153 \mu \mathrm{g} / \mathrm{m}^{3}$; by comparison, Toronto levels hover around $8 \mu \mathrm{g} / \mathrm{m}^{3}$.

About two decades ago, highincome countries, including Canada and the United States, noted the effect industrialization had on air quality and began looking for better ways to continue to develop economically, without putting the population's health at risk.

In Ontario, levels of fine particulate matter have dropped 30\% since 2004, according to the province's annual air quality report. One of the main reasons for this decline was the closure of coalfuelled electrical generation plants in

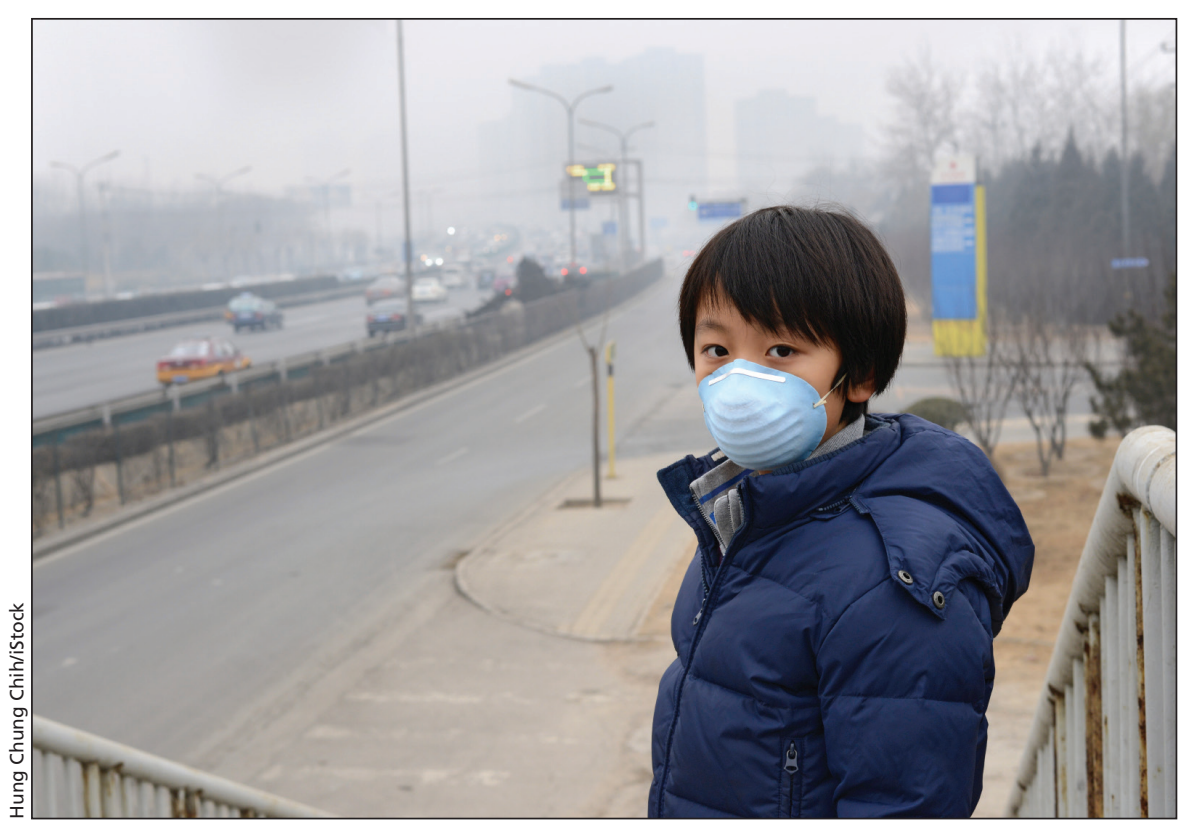

China and India have some of the highest levels of air pollution in the world.

Top 15 countries with the highest annual mean of fine particulate matter (PM 2.5)

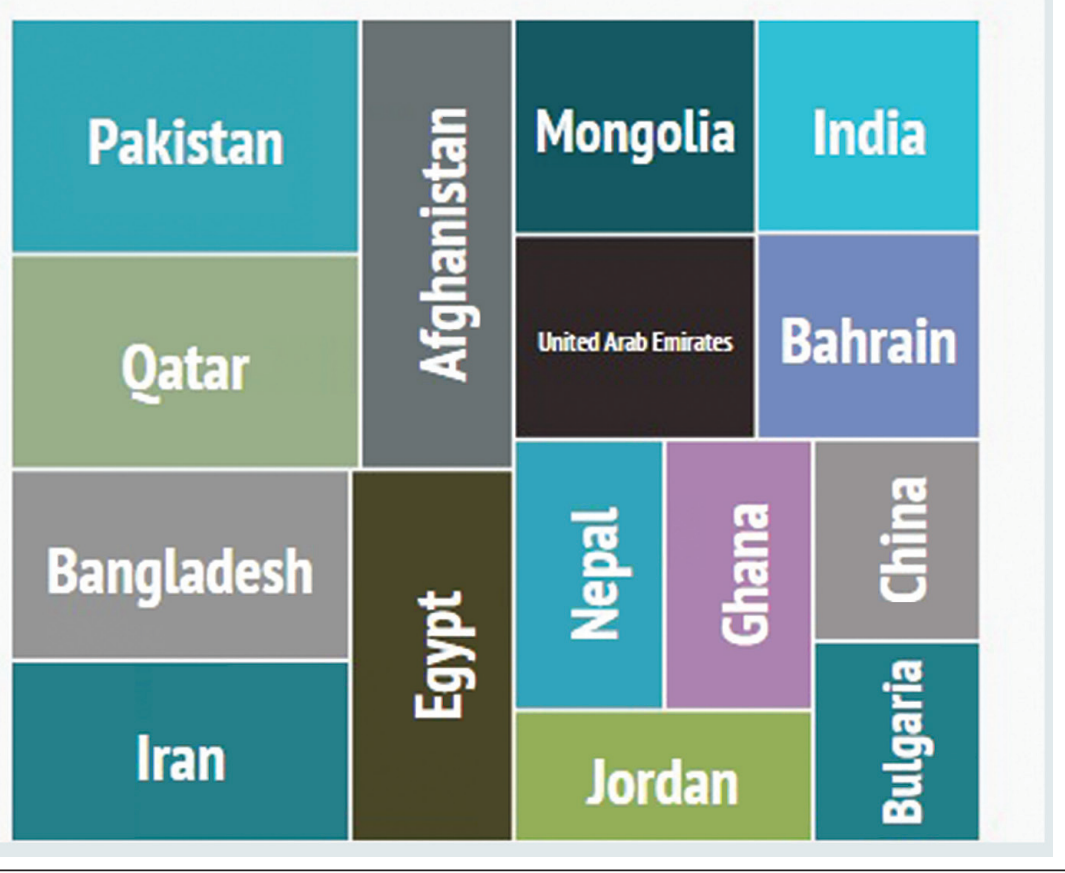

The top 15 countries with the highest annual mean of fine particulate matter (PM 2.5) 
favour of alternative sources, such as nuclear power and natural gas.

Recently, China "declared war" on air pollution, and in India, Prime Minister Narendra Modi launched the country's first air-quality index in April. These two countries have some of the highest levels of air pollution in the world.

The World Health Assembly's resolution was prepared by a number of countries, including Chile, Colombia, France, Norway, Ukraine, the US and Zambia. Canada was not a part of the discussion, but representatives were present at other topics during the assembly.

The resolution highlights strategies such as better policies to promote cleaner public transit and clean-energy sources, like solar and wind power, and reducing emissions of carbon dioxide, methane and black carbon. The resolution calls for health ministers to take a larger role in the environment debate.

"We expect member states to agree on doing more data collecting and more monitoring of the trends of how air pollution is impacting the health of the population," Neira says.

At the May 18-26 assembly in Geneva, Switzerland, Marcelo MenaCarrasco, Chile's vice-minister of environment, said he is pushing for environment ministries to join the health community to "put a human face on climate mitigation."

At the end of 2014, Chile introduced a plan to reduce emissions by over $70 \%$ clean vehicles, more cheaper and easier to buy." Mena-Carrasco says he bikes to work every day, despite having his own chauffeur.

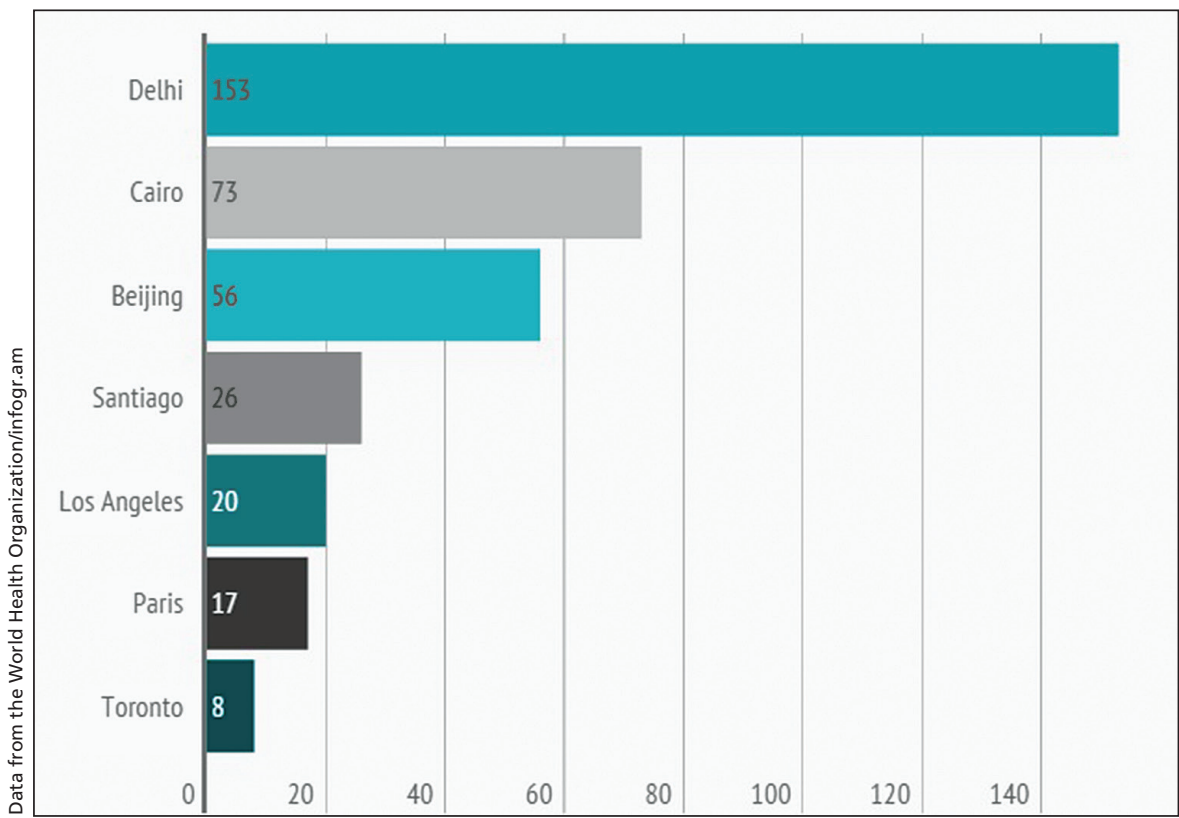

Comparing air quality in cities by their annual mean of fine particulate matter (PM 2.5)

by 2025 . It includes a new carbon tax on power plants geared to the amount of air pollution emitted, and a tax on new cars based on the fuel efficiency of the vehicle. Diesel car sales have already declined by $25 \%$, said Mena-Carrasco.

"What we're trying to do is harness the market forces to make clean energy,
Member states have proposed that next year, the World Health Assembly discuss creating a road map to guide the global response to the harmful effects of air pollution on health. Shannon Lough, CMAJ

CMAJ 2015. DOI:10.1503/cmaj.109-5077 